\title{
Enrollment of HIVIAIDs patients in Federal Medical Centre, Umuahia, Abia State, South East Zone, Nigeria
}

\author{
Nwokeukwu Huldah Ijeoma ${ }^{1}$, Chuku Abali. ${ }^{2}$, Emma-Ukaegbu Uloaku ${ }^{1}$, \\ Nwogu Kelechukwu Chukwudi. ${ }^{1}$ \\ ${ }^{1}$ Department of Community Medicine, Federal Medical Centre Umuahia, Abia State, Nigeria \\ ${ }^{2}$ Department of Ophthalmology, Federal Medical Centre Umuahia, Abia State, Nigeria \\ Email address: \\ drhiln@yahoo.com(H. I. Nwokeukwu)
}

\section{To cite this article:}

Nwokeukwu Huldah Ijeoma, Chuku Abali., Emma-Ukaegbu Uloaku, Nwogu Kelechukwu Chukwudi. Enrollment of HIV/AIDs Patients In Federal Medical Centre, Umuahia, Abia State, South East Zone, Nigeria. European Journal of Preventive Medicine.

Vol. 1, No. 1, 2013, pp. 32-36. doi: 10.11648/j.ejpm.20130101.13

\begin{abstract}
Introduction: Nigeria is one of the countries with high cases of HIV/AIDs and is a resource limited country that depends on donor agencies for control of HIV/AIDs. In Abia state there has been steady increase in the incidence of HIV from 1999 to 2010 in the sentinel survey done. It is therefore necessary to check the enrollment of HIV/AIDs in a tertiary health facility if there is a corresponding increase in the reporting of these cases. Objective: To determine the cases of HIV/AIDs that enrolled into the ART centre Methodology: Review of records in which the data in the ART Centre, Federal Medical Centre, Umuahia was collected from 2008 to 2011 and analyzed with Excel and Epi-Info. Result. The result collected: enrollment of patients 2008 (1436), 2009(948), 2010(679) and 2011(792).Out of total 3855 newly enrolled from 2008 to $2011,2480(64.3 \%)$ were newly initiated on treatment and transfer in 204(5.3\%). Females (62.8\%) are more than males $(37.2 \%)$ p value $<.05$. Children enrolled were $245(6.4 \%)$ Conclusion: There has been reduction in enrollment of cases from 2008 to 2010 with slight increase in 2011. This showed an inverse proportion of the result from sentinel survey in Abia State. There could be increase in the number of centers treating HIV/AIDs where they are going to or increase in stigmatization and under reporting. Extensive data from other centers in Abia State should be reviewed.
\end{abstract}

Keywords: Enrollment, HIV/AIDs

\section{Introduction}

This century has continued to face the challenges of the HIV epidemic where greater than 34 million people are infected with HIV. New infections are still occurring despite all effort being made to combat this. In 2006 member states of the UN got committed to universal access to HIV prevention, treatment, care and support by 2010[1]. In 2011 not only were 2.2 million people infected but also1.7million died of AIDs. According to the model of essential package of integrated health sector intervention for HIV prevention, treatment, care and support; health facility based interventions include-information and education on preventing HIV transmission, HIV testing and counseling, prevention of mother to child transmission of HIV, prevention of sexual transmission, harm reduction for injecting drug users, prevention of transmission in healthcare settings, prevention services for people living with HIV/AIDs and clinical management of people living with HIV/AIDs[2]

Care of HIV/AIDs patients has been a focus of health care in the past 2 decades requiring serious considerations and attention from professionals, government and corporate bodies. Access to antiretroviral therapy was largely restricted to few people in the developing world at the dawn of the $21^{\text {st }}$ century. This was not only due to the reason that ARVs were very expensive but also international patents that deterred the production of such drugs at cheaper and affordable prices. This situation to an extent got ameliorated in 2001 when drug producers in these developing countries started producing generic drugs by provisions made by the international trade law as well as laws passed by some developing countries enabling them to purchase generic drugs from abroad. Sequel to this drop in prices of drugs was the global expansion of treatment [3]

In 2011 ten years after the historic UN special session on HIV/AIDs search for HIV/AIDs cure has continued to be 
the concern of research and innovations. A UNAID report of March 4, 2013 said that a child born to an HIV positive mother who was not accessing care appears to be functionally cured after 18 months of treatment with triple ART drugs from the $3^{\text {rd }}$ day of life which if confirmed will be the first documented case of an HIV positive child with no detectable HIV levels and no HIV-specific antibodies [4]

Though some countries still have restrictions and bans on travel and residence due to HIV/AIDs, it is a breakthrough to note that Mongolia has removed every restriction on travel and other discriminations against people living with HIV. This was started on Feb. 15 2013[5]

Significant changes have occurred in the inpatient presentation of the HIV infected patients over the years. From the early years when patients presented with accumulating opportunistic infections highly ravaging the picture and led to an early death to the HAART era with reports of dramatic decreases in opportunistic infections and improvements in life expectancy, though evolution of inpatient HIV care has been a challenge to the clinician with diversification in the presentation of the HIV inpatient in the HAART era. [6]

The rates of hospitalizations (per 100 person-years) fell from 24.6 in 1994 to 11.8 in $2005(\mathrm{P}<0.0001)$ in a prospective cohort study of 7155 patients enrolled in the HIV Outpatient study at 10 US HIV clinics with rates of hospitalizations for AIDs opportunistic infections decreased from 7.6 in 1994-1996 to 1.0 in 2003-2005 (P < 0.0001). AIDs opportunistic infections were present at $31 \%$ of hospitalizations in 1994-1996 versus $9.5 \%$ in 2003-2005, and chronic end-organ disease conditions were present at $7.2 \%$ of such hospitalizations in 1994-1996 versus $14.3 \%$ in 2003-2005. The decreased rate of hospitalizations for HIV-infected patients during 1994-2005, was attributed mainly to reductions in the AIDs opportunistic infections. Higher CD4+ cell counts characterized patients in the highly active antiretroviral therapy era who were hospitalized more frequently for chronic end-organ conditions compared with the period 1994-1997.[7]

Also among all inpatient hospitalizations of 2,151 HIVpositive patients enrolled in Johns Hopkins Universitybased HIV clinic between January 1, 1994 and December 31, 1998 with a CD4 count within a 6-month calendar semester it was found that Hospitalization rates decreased between 1995 and 1996 but increased between 1997 and 1998 with analysis showing White race, low CD4 count, and no antiretroviral treatment were strong predictors of hospitalization for an opportunistic infection while female gender (IRR, 1.45; p <.001), African-American ethnicity (IRR, $1.22, \mathrm{p}=.05$ ), no antiretroviral treatment, and low CD4 counts were predictive of higher hospitalization rates for non opportunistic infection-related diagnoses; and female gender (incidence rate ratio [IRR], 1.45; $\mathrm{p}<.001$ ), injection drug use (IRR, 1.36; p <.001), and having received no antiretroviral therapy were strong predictors of total hospitalization.[8]
Studies done earlier in this century have shown some disparity in the hospitalization rates which was higher among the minority or disadvantage group giving clues to existing inequalities in care while inpatient utilization in children showed some dissimilarities to adults compared with previous studies as well as less pronounced racial/ethnic or gender disparities in healthcare utilization for HIV-infected children unlike adults [9, 10]

Research has also suggested that though opportunistic infection have declined with the introduction of HAARTS, there is an upsurge of decompensate liver disease and increase in admission rates of $\mathrm{HIV} / \mathrm{HCV}$ co-infected patients and IDU meaning worsened hospitalization rates for liver related complications $[8,11,12,13]$

In a country based qualitative study done in rural Kinesa district Tanzania which explored perception of and experience of barrier to accessing the national ARV programme among self-identified HIV-positive persons showed that most patients were willing to join a support group while some changed attitude to disclosure, both experienced and anticipated discrimination persisted to hinder wide spread use of ART and simple measures reduced perceived barrier initially while passive stigma remained a problem [14]

Many other studies have demonstrated changes in trend and pattern of HIV patient admission in the hospital and also in different sections of health facilities, a decline in ADI associated with patient admission and possible effects on utilization of care $[15,16,17,18,19]$

It is also noted that partnership is increasing in African region in order to raise awareness of HIV/AIDs.

A Nigerian Survey revealed a National prevalence of $4.1 \%$, this ranged between $1.0 \%$ in Kebbi State to $12.7 \%$ in Benue State with Abia state having 7.0 prevalence rate. The dynamics of HIV/AIDs Nigeria is driven by ignorance, poverty and disease HIV is a "social disease" disrupting the fabrics of society through stigmatization of sufferers, as well as through years of education and of productivity lost. The fight against HIV especially in developing countries has to be the duty of all stake holders. While an effective vaccine remains to be found, education has been described as a social vaccine for the HIV pandemic [20]

There has been persistent increase in the survey result for prevalence of HIV in Abia State (1999 (3\%), 2001 (3.3\%) $2003(3.7 \%), 2005(4 \%), 2008(5 \%), 2010(7.0 \%))$, it is therefore necessary to find out if there is corresponding increase in the enrollment of HIV in the only Federal health facility in the State.

Objective: To determine the cases of HIV/AIDs that enrolled into the ART centre

\section{Methodology}

Federal Medical Centre, Umuahia is the only Federal tertiary health facility in Abia State, Southeastern Nigeria. The facility started the ART Centre in 2006 where the Anti retroviral drugs are given free. Data was collected from 
records under the following headings:-Newly Enrollment, newly initiated and Transferred in from 2008 to 2011.

The data was analyzed with Excel and Epi-info.

\section{Result}

The result collected: enrollment of patients 2008 (1436), 2009(948), 2010(679) and 2011(792). Out of total 3855 newly enrolled from 2008 to 2011,2480 (64.3\%) were newly initiated on treatment and Transfer in 204(5.3\%). Females $(62.8 \%)$ are more than males $(37.2 \%) \mathrm{p}$ value $<.05$. Children enrolled were $245(6.4 \%)$ The number of cases that enrolled was more in 2008, followed by 2009 and 2011 and then 2010 . This showed yearly enrollment with $32 \%$ in $2008,25 \%$ in $2009,18 \%$ in 2010 and $20 \%$ in 2011 The patients that started Anti retroviral was more tha $60 \%$ while 2011 had the lowest number that started ART 47\% while in 2009 with highest percentage $79 \%$. The yearly transferred in were more in 2008 and 2011.

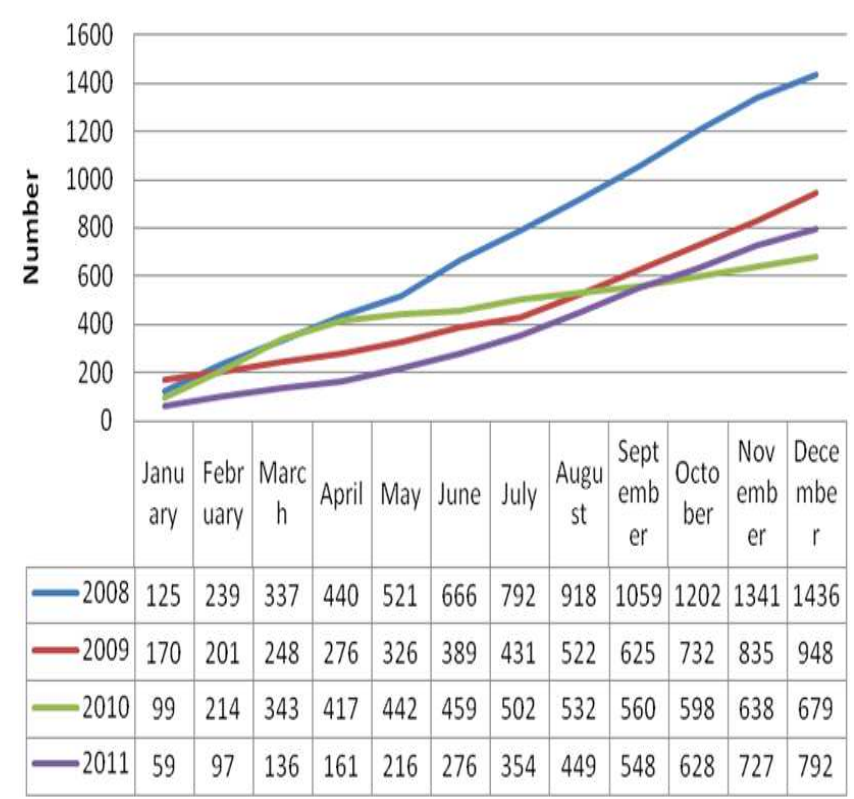

Figure 1. Cumulative enrollment of HIV from 2008 to 2011

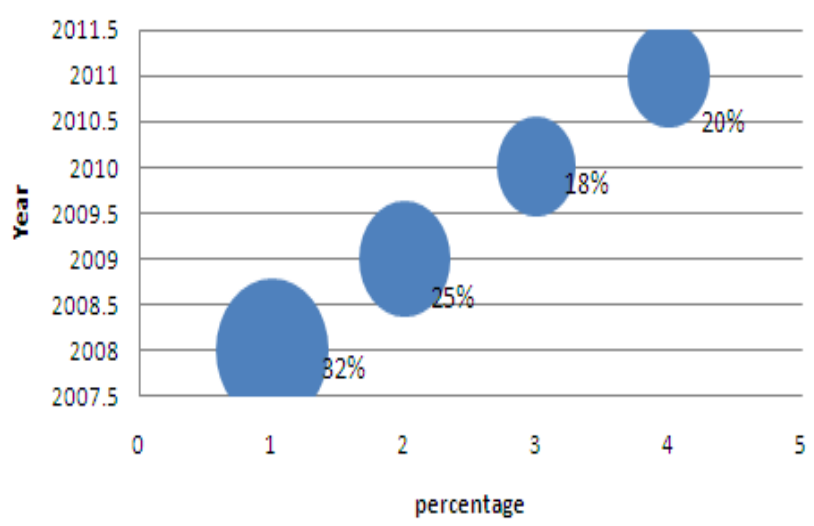

Figure 2. Yearly enrollment percentage over the total (2008- 2011) enrollment

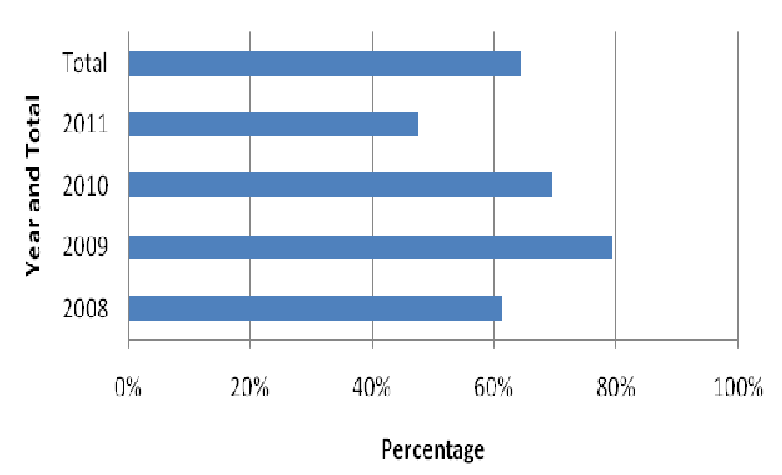

Figure 3. Clients that started ART out of the number enrolled yearly and total

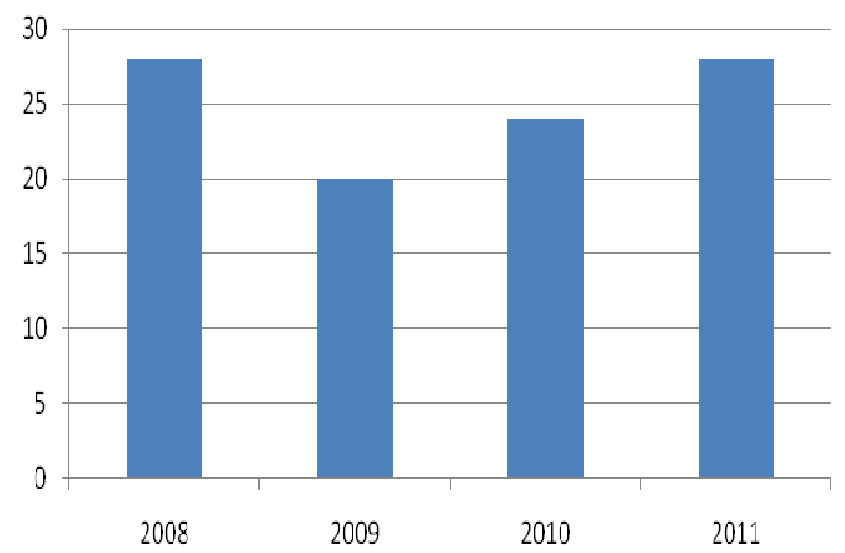

Figure 4. Yearly transferred in out of total transferred in

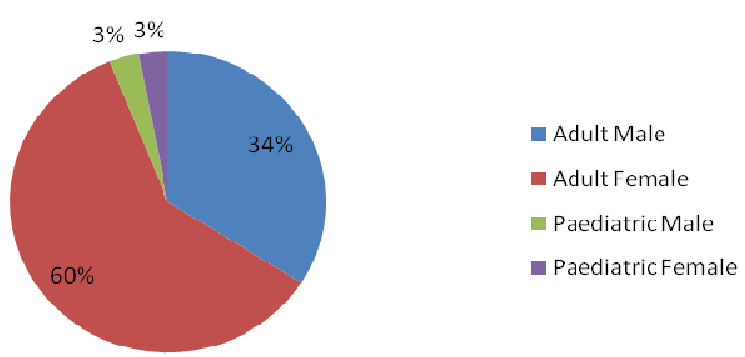

Figure 5. Enrollment of HIV/AIDs by Sex and Age

There is significant difference between the enrollment of adult female $(60 \%)$ and adult male $(34 \%)$. The enrollment of the pediatric male and female were the same $3 \%$ each.

\section{Discussion}

The enrollment of HIV/AIDs patient in the Health facility reduced in the subsequent years which are in contrast with the result of sentinel survey in the country which showed increase in the prevalence of HIV from 1999 to 2010 in Abia State. Instead of increasing in enrollment due to increase in prevalence of HIV in the State there was decrease. This could be due to the fact that the patients are not enrolling into the services, because of the stigmatization attached to it or many are not testing to know their status. This patient could be going to other health facilities that are offering the ART services. 
This study showed that more than $60 \%$ of people enrolled were initiated on the treatment this is in contrast to the study done in Rwanda where less than 50\% were initiated on treatment and care with 90 days of diagnosis[21] and also in Tanzania[22] There has been different levels of CD4 cell count for initiation into treatment of HIV/AIDs, Initially it was a the level of 200 cells $/ \mathrm{mm}^{3}$ and later 350 cells $/ \mathrm{mm}^{3}$ but now it is recommended that all cases should be started on treatment and this will actually improve the rate of cases that are initiated on treatment. However in this study as seen in fig 3 those that started ART were less in 2011 and highest in 2009.

This study also showed greater number of the patients that enrolled was females this is in contrast with the study were males were more than $60 \%$ [23]. However similar results were gotten in some studies where females enrolled were more than males [24, 25]. These discrepancies in sex may be due to the fact that more females are infected since there is easy infectivity in females or more women seek for care. The former is more realistic. It was also noted that in children there was no difference in the sexes that enrolled. The enrollment of male and female in pediatrics are the same fig 5 , this could be due to, the mode of transmission in both are the same mainly mother to child transmission. The children percentage in this study is lower than what is reported in HIV/AIDs Resource Centre in Bori General Hospital, Khana Local Government Area, and Rivers State, Nigeria of $12 \%$ [26]

In this study, more patients were transferred in 2008 and 2011 in fig 4; this could be that there were more support, financial, material including drugs and human resources for patients from other centers to be accepted into the programme in the centre.

\section{Conclusion and Recommendation}

There has been reduction in enrollment of cases from 2008 to 2010 with slight increase from 2010 to 2011 . This showed an inverse proportion of the result from sentinel survey in Abia State. There could be increase in the number of centers treating HIV/AIDs where they are going to or increase in stigmatization and under reporting. Extensive data from other centers in Abia State should be reviewed. There should be increase in awareness creation of need for counseling, testing and enrollment into treatment and care.

\section{Ethical Consideration}

Ethical approval was gotten from the ethical committee of Federal Medical Centre, Umuahia: Assigned number: FMC/QEH/G.596/Vol.10/041

\section{Acknowledgement}

The workers in the ART centre of Federal Medical Centre, Umuahia are hereby acknowledged for generation and collection of data.

\section{Competing Interest}

The authors declare no competing interest.

\section{Approval by the Authors}

The authors approved the publication of the manuscript.

\section{References}

[1] World Health Organization; HIV/AIDs. Universal Access to HIV/AIDs prevention, treatment and care)

[2] Towards universal access by 2010: How WHO is working with countries to scale up HIV prevention, treatment, care and support. Geneva: WHO; 2007. Available from http://www.who.int/hiv/pub/advocacy/universalaccess/en/ (Accessed on 8 March 2013)

[3] Universal access to HIV/AIDs Treatment: International HIV/AIDs Charity.www.avert.org/universal access.htm

[4] UN welcomes news of HIV baby who appears to be cured of by treatment: UN news Centre. www.un.org

[5] UN applauds Mongolia for removing HIV-related travel restrictions. UN News office

[6] Pulvirenti J. Inpatient care of the HIV infected patient in the highly active antiretroviral therapy (HAART) era. Current HIVResearch. 2005; 3(2):133-145. doi: $10.2174 / 1570162053506964$

[7] Buchacz K, Baker RK, Moorman AC, Richardson JT, Wood KC, Holmberg SD, Brooks JT; HIV Outpatient Study (HOPS) Investigators.

[8] Rates of hospitalizations and associated diagnoses in a large multisite cohort of HIV patients in the United States, 19942005. AIDs. 2008 Jul 11; 22(11):1345-54. doi: 10.1097/QAD.0b013e328304b38b.

[9] Gebo KA, Diener-West M, Moore RD. Hospitalization rates in an urban cohort after the introduction of highly active antiretroviral therapy. Journal Acquired Immune Deficiency Syndrome. 2001 Jun 1; 27(2):143-52

[10] Fleishman JA, Gebo KA, Reilly ED, Conviser R, Christopher MW, Todd KP et al; HIV Research Network. Hospital and outpatient health services utilization among HIV-infected adults in care 2000-2002. Medical Care. 2005 Sep; 43(9 Suppl):III40-52.

[11] Rutstein RM, Gebo KA, Siberry GK, Flynn PM, Spector SA, Sharp VL et al.Hospital and outpatient health services utilization among HIV-infected children in care 2000-2001. Medical Care. 2005 Sep; 43(9 Suppl):III31-9

[12] Gebo KA, Diener-West M, Moore RD. Hospitalization rates differ by hepatitis $\mathrm{C}$ satus in an urban HIV cohort. Journal Acquired Immune Deficiency Syndrome. 2003 Oct 1; 34(2):165-73.

[13] Rodríguez-Vidigal FF, Habernau A.[Cause of hospitalization in patients with human immunodeficiency virus infection in a rural area. Role of chronic liver disease]. Enfermedades Infecciosas Microbiologia Clinica. 2004 Mar; 22(3):138-41. 
[14] Gebo KA, Fleishman JA, Moore RD: Hospitalizations for metabolic conditions, opportunistic infections, and injection drug use among HIV patients: trends between 1996 and 2000 in 12 states. Journal Acquired Immune Deficiency Syndrome. 2005 Dec 15; 40(5):609-16.

[15] Mshana GE, Wamoyi J, Busza J, Zaba B, Changalucha J, Kaluvya S, Urassa M. Barriers to accessing antiretroviral therapy in Kisesa, Tanzania: a qualitative study of early rural referrals to the national program. AIDs Patient Care and STIs. September 2006, 20(9): 649-657. doi: 10.10.1089/apc.2006.20.649

[16] Casalino E, Wolff M, Ravaud P, Choquet C, Bruneel F, Regnier B. Impact of HAART advent on admission patterns and survival in HIV-infected patients admitted to an intensive care unit. AIDs. 2004 Jul 2; 18(10):1429-33

[17] HIV Research Network. Hospital and outpatient health services utilization among HIV-infected patients in care in 1999. Journal Acquired Immune Deficiency Syndrome. 2002 May 1; 30(1):21-6.

[18] Berry SA, Fleishman JA, Moore RD, Gebo KA; HIV Research Network. Trends in reasons for hospitalization in a multisite United States cohort of persons living with HIV, 2001-2008. Journal Acquired Immune Deficiency Syndrome. 2012 Apr 1; 59(4):368-75. doi: 10.1097/QAI.0b013e318246b862.

[19] Wolff AJ, O'Donnell AE. Pulmonary manifestations of HIV infection in the era of highly active antiretroviral therapy. Chest. 2001 Dec; 120(6):1888-93.

[20] Charurat M, Blattner W, Hershow R, Buck A, Zorrilla CD, Watts DH et al. Women And Infants Transmission StudyChanging trends in clinical AIDs presentations and survival among HIV-1-infected women. J Womens Health (Larchmt). 2004 Jul-Aug; 13(6):719-30.
[21] Garbati, Musa A, Abba, Abdullah A, Kabrang, Danjuma N and Yusuph H HIV/AIDs in Northeastern Nigeria: A review Journal of Infectious Diseases and Immunity Vol. 3(10), pp. 176-182, 15 October, 2011 Available online at http://www.academicjournals.org/JIDI ISSN 2141-2375 (C)2011 Academic Journals

[22] Kayigamba FR, Bakker MI, Fikse H, Mugisha V, Asiimwe A, et al. (2012) Patient Enrolment into HIV Care and Treatment within 90 Days of HIV Diagnosis in Eight Rwandan Health Facilities: A Review of Facility-Based $\begin{array}{llll}\text { Registers. PLoS ONE } & \text { 7(5): }\end{array}$ doi:10.1371/journal.pone.0036792

[23] Asgeir Johannessen, Ezra Naman, Bernard J Ngowi, Leiv Sandvik, Mecky I Matee et al, Predictors of mortality in HIV-infected patients starting antiretroviral therapy in a rural hospital in TanzaniaBMC Infectious Diseases 2008, 8:52 doi:10.1186/1471-2334-8-52

[24] Anant A. Takalkar, G.S. Saiprasad, V .G. Prasad, Narendra S. Madhekar: Study of Opportunistic Infections In HIV Seropositive Patients Admitted to Community Care centre (CCC), KIMS Narketpally. Biomedical Research 2012; 23 (1): $139-142$

[25] Akinsegun Akinbami, Adedoyin Dosunmu, Adewumi Adediran, Sarah Ajibola, Olajumoke Oshinaike et al: CD4 Count Pattern and Demographic Distribution of TreatmentNaïve HIV Patients in Lagos, Nigeria AIDs Research and Treatment Volume 2012 (2012), Article ID 352753,6pagesdoi:10.1155/2012/352753

[26] A.S. Olufemi, O.M. Simidele, J.A. Kayode: Pattern Of Presentation Among Hiv/AIDs Patients In Makurdi, Nigeria. The Internet Journal of Epidemiology. 2009 Volume 6 Number 2. DOI: $10.5580 / 1200$

[27] http.//www.thetidenewsonline.com/2011/09/28/4746-enrolfor-livands-treatment/feed. 